making her cocoon under a projecting portion of the lookingglass frame. She had already made a bunch, apparently hollow, of the fine wrinkled silk often found inside of spiders' cocoons. She attached her spinnerets to the silk already spun, then drew them away six or eight millimetres, spinning out a short band of fine threads which she attached again near the starting point thus making a short loop. She then made other loops, moving a short distance at each stroke, without following any regular direction, until tired; then rested a few minutes, and went on with another part of the cocoon. After half an hour the spider rested beneath the cocoon, with the opening of her ovaries under the centre, and discharged her eggs upwards between the threads into it. The eggs were very soft and flexible, and formed, with a small amount of liquid, a jelly-like mass; which became spherical as soon as it found room in the cocoon. The lower part protruded between the loose threads without flowing through. In a minute the eggs were all laid, and the spider began immediately to strengthen the lower part of the cocoon.

Several times I have had females of Epeira patagiata and Epeira (Argiope) riparia lay their eggs in bottles; but, although the cocoons were made, and, in the case of $\boldsymbol{E}$. riparia, finished even to the smooth outside, the eggs were laid loose in the bottle. The reason seems to be that, owing to the narrowness of the bottle, after the spider had made the first part of the cocoon, she could not get into a proper position to discharge her eggs into it.

J. H. Emerton.

\title{
List of Noctuidae taken about Newton, Mass.
}

The following list of Noctuidae, collected for the most part by myself, in Newton and vicinity, during the last few years, may be of interest. For the identification of a large number of my specimens I am indebted to the kindness of Mr. A. R. Grote. I have several species still undetermined, which I will add as soon as I learn their names. 
For the sake of conciseness, the following abbreviations are used :

$$
\begin{array}{lll}
\text { c. }=\text { common. } & \text { b. a. = on baked apples. } & \text { Mh. = in March. } \\
\text { n. = not. } & \text { l. = at light. } & \text { Ap. = in April. } \\
\text { r. = rare. } & \text { q. = at rest. } & \text { My. = in May. } \\
\text { t. = rather. } & \text { s. = at sugar. } & \text { Jn. = in June. } \\
\text { u. = uncommon. } & \text { w. = in - woods. } & \text { Jl. = in July. } \\
\text { e. = early. } & \text { coc. = cocoon on or under. } & \text { Au. = in August. } \\
\text { g. = late. } & \text { lrv. = larva found on. } & \text { Sp. = September. }
\end{array}
$$

Leptina ophthalmica. R. I. Jn. “ Dcubledayi. One q. Jn. Pseudothyatira cymatophoroides. T. c. 1. s. Jn.

"6 expultrix. T. c. l. s. Jn.

Habrosyne scripta. N. u. s. Jn.

Eutolype Rolandi. R. 1. Ap.

Dicopis muralis. $\quad$ R. 1. Ap. My.

" Thaxterianus. L. Ap. 14.

Raphia frater. N. c. 1. Jn. Jl.

Charadra deridens. R. l. s. Jn. e. Jl. " propinquilinea. L. Jn. 4. Harrisimemna sexguttata. R. 1. Jn. Lrv. Syringa, Sp.

Apatela occidentalis. N. c. 1. Jn. Lrv. Ulmus.

" lobeliae. T. r. 1. Jn. Lrv. Quercus.

spinigera. T. r. 1. My. Jn. Au.

innotata. One 1. Jn.

americana. C. Lrv. Acer and Betula.

“ dactylina. T. r. Jn. Lrv. Betula and Salix, Sp.

" luteicoma. Jn. Lrv. Fraxinus, Sp.

‘brumosa. C. s. 1. My. Lrv. Salix and Betula, Sp.

" noctivaga. N. c. s. My. Jn.

" afflicta. R. 1. Jn. Coc. under Juglans.

" clarescens. (У. Jn. Lrv. Pyrus malus.

" ovata. N. u. in Quercus w. g. Jn.

" hamanelis. C. Jn. in Quercus w. Lrv. Castanea.

" dissecta. T. r. s. l. Jn.

" albarufa. R. l. e. Jl.

" exilis. R. l. Jn.

" sperata. N. u. 1. Jn.

" lithospila. Q. in Juglans w. g. Jn.

"oblinita. C. l. Jn.

" lanceolaria. R. 1. Au.

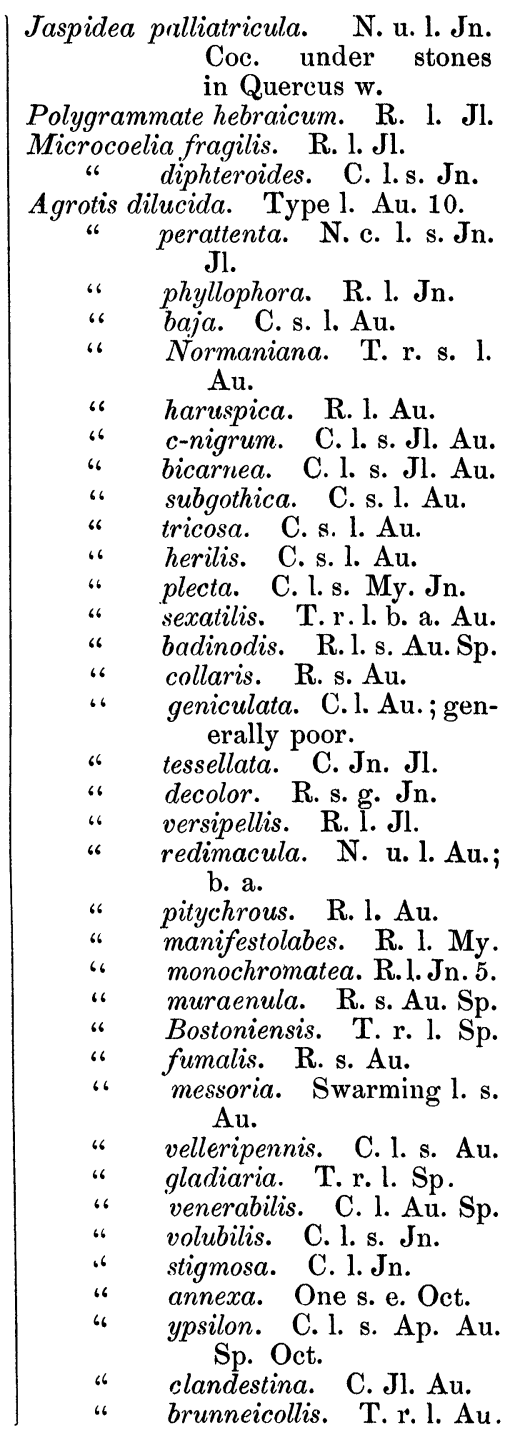


Agrotis alternata. R. s. Au.

" cupida. R. l. Au.

" claviformis. R.l. My.

" lubricans. C. 1.Jn.Jl. Au.

" pressa. R. s. Jn. 15-27.

" prasina. C. I. Jn. Jl. Au.; q. in Quercus w.

"occulta. N. c. l. s. Jn.

Adita chionanthi. L. Au. 7.

Mamestra purpurissata. C. 1. Au.

"latex. N. c. l.; q. in Quercus w.

"adjuncta. C.Jn.

" grandis. R.l. Jn.

" subjuncta. C. I. Jn. Jl.

" atlantica. C. 1. s. Jn.

" vicina. C. l. g. My. Jn.

" legitima. T. r. l. Au.

" lilacina. L. Jl. 15.

" assimilis. R. s. l. Jn. 19Jl. 10.

" trifolii. C.

" detracta. N. c. Jn. 20Jl. 15.

" lorea. C. l. Jl. Au.

" rosea. N. u. 1. My. $25-$ Jn. 15.

" vindemialis. R. I. Jn. Jl.8.

" renigera. C. Au.

Dianthoecia meditata. C. l. Au.

" modesta. N. u. l. My. Jn.

Hadena loculata. R. l. Au.

" devastatrix. C.

" sputatrix. C.

" congermana. R. s. 1 .

" suffisca. R. l. Au.

" arctica. C.

" Bridghami. R. l. Jl.

" vultuosa. C. l. Au.

" lignicolor. C. Jl.

" vulgaris. R. I. Jl.

" verbascoides. C. Jl.

" sectilis. R. I. Jl.

" cariosa. R. I. Jn. 15-Jl.

12.

" inordinata. T. r. l. Jn.

" finitima. C. l. Jn.

" diversicolor. R. 1. Au. Sp.

" mactata. R. s. Au.

" miselioides. C.

" arna. N. u. s. l. Jn.

Perigea xanthioides. R. l. Jn. Au. " luxa. R. l. Jl.

" fabrefacta. B. a. Sp. 21.

Dipterygia scabriuscula. R. l. s. Au. Sp.

Hyppa xylinoides. C. My.; Lrv. under boards, Ap.
Valeria Grotei. $\quad$ R. 1. Ap. My.

Chytonix iaspis. R. 1. Jl.

Homohadena badistriga. Q. Jl. Lrv. Lonicera.

Copipanolis cubilis. R. 1. Mh. Ap. My.

Actinotia ramosula. C. My. Au.

Morrisonia evicta. T. r. l. My. " vomerina. N. u. l. My.

Callopistria mollissima. T. r. s. Jn. monetifera. R. l. s. Jn.

Prodenia commelinae. R. s. Au. " ornithogalli. R. l. Jl.

Trigonophora periculosa. R. l. q. in Quercus w. Jl. Au.

Euplexia lucipara. C. 1. My. Jn.

Brotolomia iris. N. u. l. s. Jl.

Nephelodes minians. T. r., almost always in poor condition, Au.

" violans. Like the last.

Tricholita semiaperta. R. l. Au.

Helotropha reniformis. C. l. Au.

" atra. R. s. Jl.

Gortyna purpuripennis. R. 1. My. Jn.

" sera. C. Jl. Au.

" nictitans. C. Au.

" immanis. N. c. l. Au.

" nitela. R. l. Sp.

" nebris. C. 1. Sp.

" speciosissima. R. l. Sp.

" cerussata. K. l. Sp.

" rutila. R. I. Sp.

“ purpurifascia. N. u. 1.

$$
\text { Sp. Oct. }
$$

Achatodes zeae. R. l. Jl.

Arzama obliquata. R. 1. Jn.

Amolita fessa. R. l. Jl.

Platysenta atriciliata. R. 1. Jn.

Arsilonche henrici. C. 1. My. 5Jn. 10.

Heliophila pallens. C. Jn. Jl. Au.

"Harveyi. C. Jn. Jl. Au.

" phragmitidicola. C. Jn. Jl. Au.

" adonea. C. Jn. Jl. Au.

" commoides. C. Jn. Jl. $\mathrm{Au}$.

"unipuncta. C. Jn. Jl. Au.

" pseudargyria. C. Jn. Jl. Au.

Caradrina miranda. C. l. Jn.

Pyrophila pyramidoides. C.

" tragopoginis. C. s. Jl.

Orthodes infirma. 'T. r. s. Jl.

" cynica. C. s. Jl.

Pseudorthodes enervis. R. I. Jl. 
Graphiphora oviduca. C. s. l. My. " incerta. R. b. a. Ap. " alia. C. 1. Ap. My.

Crocigrapha Normani. N. u. 1. My. Calymnia orina. T. r. l. q. Jl. Au. Ipimorpha pleonectusa. R. 1 . Au. Orthosia helva. R. s. Au.

" ferrugineoides. C. 1. s. Sp. Oct. Flying about Pinus before dark in November.

" infumata. R. l. Au.

Glaea viatica. At Wellesley, Mass. (Denton.)

" sericea. R. l. and on Pinus Oct.

“ apiata. R. l. Oct.

" pastillicans. R. s. Oct.

" carnosa. At Jamaica Plain, Mass.

Jodia rufago. R. b. a. Ap.

Eucirroedia pampina. C. 1. s. Sp.

Xanthia togata. C. l. Sp.

Scopelosoma devia. R. s. Ap.

" Morrisoni. C. s. l. Ap.

"Walkeri. C. s. Ap. Sp.

" vinulenta. R. l. Ap.

" tristignata. T. r. l. s. Ap.

Scoliopteryx libatrix. C. s. Ap. My. Ju. Jl. Au. Sp. Oct. Lrv. Populus.

Lithophane disposita. N. u. s. Ap. "6 petulca. C. s. Ap. Oct. "Bethunei. C. l. s. Ap. Oct.

" fagina. R. l. Ap.

" cinerea. C. l. s. Mh. Ap. My. Sp. Oct. Lrv. Rosa and Negundo aceroides.

" pexata. R. s. l. Ap. Oct.

"Thaxteri. R. l. s. My. Oct. Anytus sculptus. C. l. Sp.

Calocampa nupera. C. l. s. Ap. My. Sp. Oct.

" cineritia. R. b. a. l. Ap. My.

. curvimacula. T. r. 1. s. Ap. My. On Pinus in Oct. Lrv. eats Iris.

Lithomia germana. R. l. Sp.

$X$ ylomiges confusa. C. 1. My.

Cucullia convexipennis. R. I. Jl.

" asteroides. R. l. Jn.

" intermedia. C. 1. Jn.

Crambodes talidiformis. R. 1 . Jl.

Nolaphana Zelleri. C. l. s. Ap. My.
Anomis erosa. One l. Au.?

Aletia argillacea. R. I. Sp.

Marasmalus ventilator. T. r. l. Jn. $\mathrm{Jl}$.

" histrio. N. u. 1. Jn.

Ingura abrostoloides. R. l. Jl.

" dilineata (fide Morrison). R. l. Jl.

Calpe canadensis. R. I. Jl.

Telesilla cinereola. C.

Abrostola ovalis. T. 1. l. Jn. Au.

Plusia purpurigera. R. I. Jn. Jl.

Lrv. Thalictrum cornuti.

" aerea. C. l. Jl.

" balluca. R. l. Au.

" contexta. T. r. l. Jn. Jl.

“Putnami. N. u. l. Jn. Jl.

“ formosa. At Wellesley, Mass. (Denton.) precationis. $\mathrm{C}$. octoscripta. R. 1. Sp. viridisignata. R. l. Au.

epigaea. R. in meadows, Jl.

" simplex. C.

Lelipolys perscripta. At Wellesley, Mass. (Denton.)

Rhodophora florida. T. r. 1. and on Primula.

Tamila nundina. R. I. Jl.

Lygranthoecia brevis. R. l. Au.

$$
\begin{array}{ll}
\text { " arcifera. } & \text { R. l. Sp. } \\
\text { " } & \text { Spraguei. } \\
\text { R. l. Au. Auta. } & \text { C. }
\end{array}
$$

Melaporphyria immortua. T. r., flies by day in meadows, Jn.

Pyrrhia exprimens. N. u. l. Au.

" angulata. R. 1. Jl.

" illiterata. R: l. Au.

Tarache candefacta. C. I. Jn. " erastrioides. C. l. Jn.

Chamyris cerintha. C. I. Jn. Jl.

Eustrotia obaurata. R. l. Jn.
" synochitis. C. 1. My. Jn.
" carneola. C. l. My. Jn.
“ apicosa. C. 1. My. Jn.
" muscosula. C. l. My. Jn.
" concinnimacula. C. 1 . My. Jn.

Lithacodia bellicula. C. in meadows, Jn.

Exyra Rolandiana. (See below.).

Prothymia rosalba. T. r. 1 . and in meadows, Jn. - Jl. 10. 
Drasteria erechtea. $\quad$ C.

Euclidia cuspidea. T. r. s. l. My. Jn. Melipotis limbolaris. R. in roads; I. Jl. Parthenos nubilis. T. r. q. l. s. Jn. Jl. Catocala epione. C. q. and flying by day in and on the borders of woods.

desperata. R. q. Au. retecta. T. r. q. s. Au. flebilis. R. q. l. Au.

insolabilis. T. r. l. s. Au. residua. R. s. Au. obscura. T. r. l. q. s. Au. tristis. Locally c. q. Au. relicta. R. s. Sp. unijuga. R. q. Au. Briseis. R. 1. s. Au. Lrv. Salix Jn. 29. concumbens. C. q. l. s. Jl. $\mathrm{Au}$.

amatrix. C. q. l. s. Jl. Au. cara. C. l. s. q. Au. coccinata. R. q. Jl. Au. Sp. ultronia. N. u. l. q. Au. parta. C. l. s. q. Lrv. Salix and Populus dilatata $\mathrm{Au}$. $\mathrm{Au}$. ilia. C. q. Lrv. Quercus

innubens. R. l. Au. cerogama. T. r. q. s. Au. palaeogama. N. u. q. s. Jl. $\mathrm{Au}$.

" var. phalanga. R. q. Au.

" habilis. C. s. 1. Au.
Catocala antinympha. C. q. s. 1. Jl. $\mathrm{Au}$.

“ badia. T.r. l. Au. serena. R. s. Jl. polygama. T. r. l. s.q. Au. formula. R. q. Au. grynea. C. s. l. Jl. Au. praeclara. R. q. l. s. Jl. Au.

fratercula. R. q. Au. gracilis. C. q. Au. amica. C. q. Jl. Au. lineella. C. q. Jl. Au.

Panopoda rufimargo. T. r. l. s. Jn. Jl. Lrv. Quercus. carneicosta R. l. Au.

Phoberia atomaris. C. in open woods and l. Ap. My.

Pseudolimacodes niveicostatus. R. 1 . Jl.

Parallelia bistriaris. C. 1. Jn.

Poaphila quadrifilaris. C. 1 . and in meadows, Jn.

Zale horrida. T. r. l. s. My. Jn.

Homoptera edusa. T. r. My. - Nov.

" Saundersii. R. s. Au.

“ lunata. T. r. My.- Nov.

" minerea. R. l. q. My. Jn.

" calycanthata. R. 1. Jn.

" unilineata. R.s. My.

" obliqua. T. r. Jn.

Ypsia aeruginosa. N. u. q. 1. My. Jn. undularis. R. I. q. Jn.

Spargoloma umbrifascia. T. r. l. Jn. Homopyralis tactus. C. s. l. Jn. Jl.

The new species mentioned in the above list is described as followed by Mr. Grote, in a letter.

"Exyra Rolandiana n. sp. $\delta, \%$. Several specimens reared by Mr. Roland Thaxter belong to a form allied to $E$. fax Grote, but are larger, the $\delta$ expanding 22 , the $\$ 18 \mathrm{~mm}$. The fore wings are deep purple in the male, with a cellular yellow spot; a large yellow patch extends from the median vein to the internal margin, divided indistinctly on the median space exteriorly by the median shade. The base of the wing is in both sexes of a more brilliant purple red. The female shows the yellow markings of the male, but the wing is almost blackish beyond the base, not purple. Fringes concolorous with the wing, not tipped with orange as in E. fax. Hind wings above and all wings beneath immaculate, in the male slaty blackish, in the female black. Thorax, head and fore femora orange red or purple; anal tuft of the male reddish. Abdomen like the hind wings; antennæ yellowish. This appears to be a larger and more highly colored form than E. fax, which Mr. Ridings brought from Georgia. - A. R. Grote." 
The larvæ of Exyra Rolandiana may be found in the smaller leaves of Sarracenia purpurea, in this vicinity, as soon as the snow is off the ground, early in the spring, apparently having moulted two or three times; they are then of a dull reddish brown and about six mm. long. As soon as the weather grows warmer, they increase in size rapidly, and, having eaten the leaf in which they have hibernated, betake themselves to the larger leaves, which they begin to eat, after having made a hole near the base to let the water out, and after having spun a close web over the mouth. The larva reaches its full growth about the first of May and later, when it is about $20 \mathrm{~mm}$. long, of a dull carmine or brown color, lighter, sometimes white, between the segments. The cocoon is spun in the leaf, of loose white silk, the larva changing to a pupa a few days after spinning. The imago appears early in June. There is a good deal of variation in the color of the females, some being much brighter than others. The following are the extreme measurements of both sexes: males 26-20 mm., females 21-16 mm. In its habits it resembles $\boldsymbol{E}$. semicrocea, generally backing down towards the bottom of the leaf, when disturbed, and using its wings in ascending. I notice that the frenulum at the base of the wings is very long in this species, and, as well as I could see, the moth seems to use it when crawling up the leaf. This species is very delicate and difficult to rear. I have observed four varieties of ichneumon which prey upon the larva, but they have not been determined.

Roland Thaxter.

\section{Proceedings of the Club.}

$\S 20$. What are the Causes of Assembling among Insects? Some of the phenomena of "assembling" among insects were mentioned. This is for sexual purposes sometimes, but not always. Insects are sometimes attracted fiom great distances, so that many individuals of a species which is not common may be drawn together at one place. Insects are sometimes attracted to their mates who are in such situations as to preclude the possibility that they could have been seen, as for instance, in a pocket. It is evident that scent is some- 

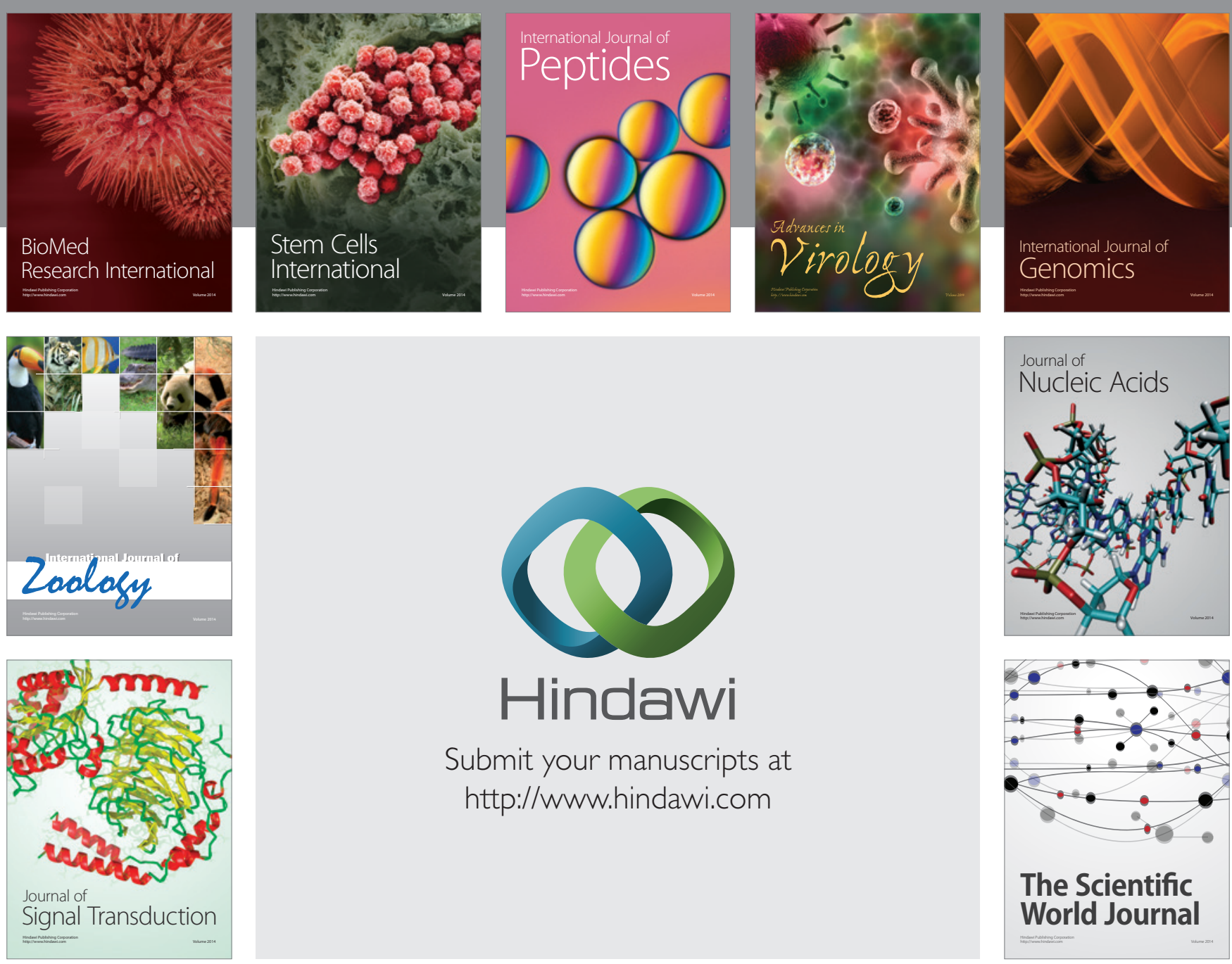

Submit your manuscripts at

http://www.hindawi.com
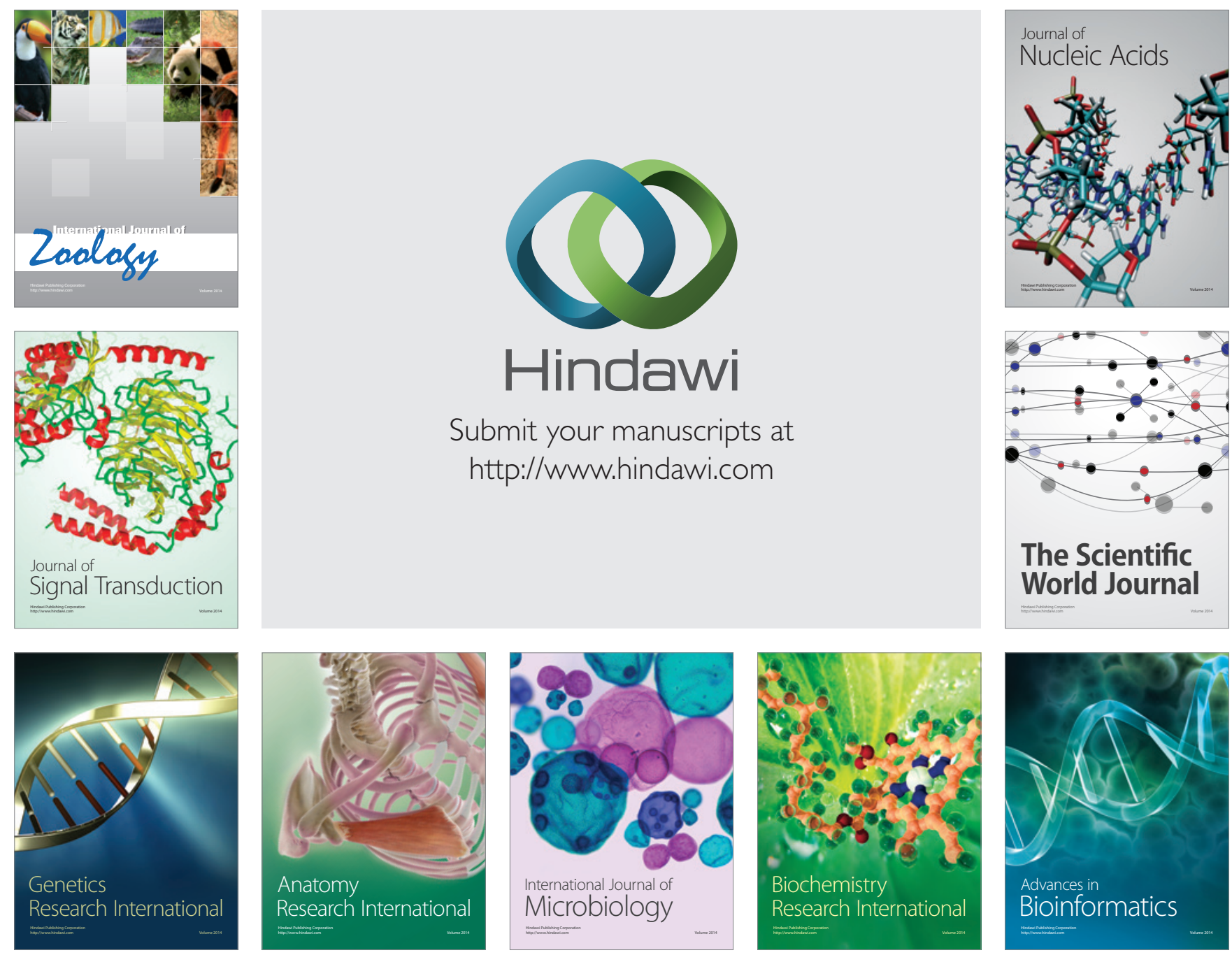

The Scientific World Journal
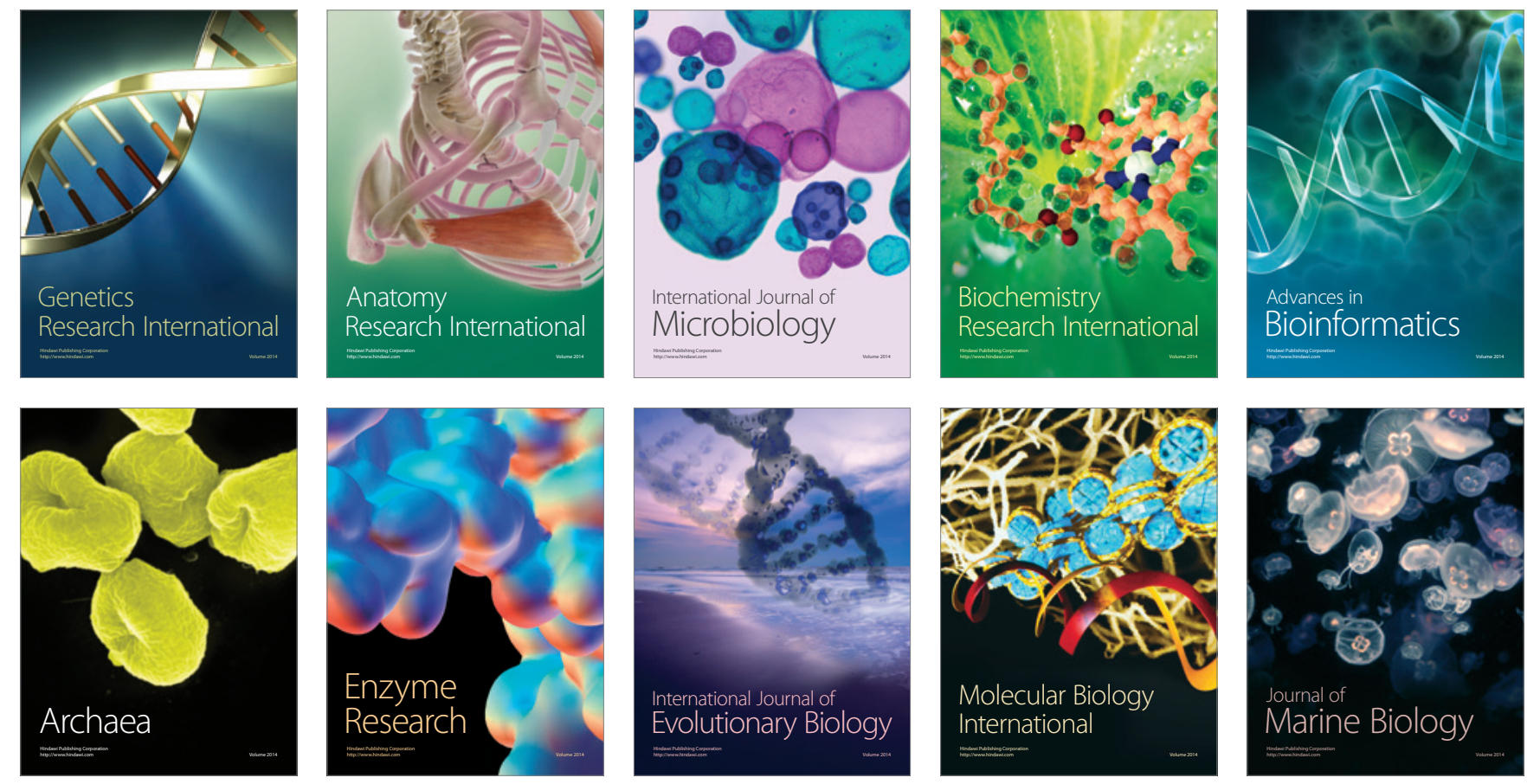